\title{
Determination of Lisinopril in Bulk and Pharmaceutical Formulations by Cloud Point Extraction-A Green Method
}

\author{
V. Mallikarjuna Sarma1, N. V. S. Venugopal ${ }^{2 *}$, L. Giribabu ${ }^{3}$ \\ ${ }^{1}$ Department of Chemistry, P. R. Government College (A), Kakinada, Andhrapradesh, India \\ ${ }^{2}$ Department of Chemistry, Institute of Science, GITAM University, Visakhapatnam, Andhra Pradesh, India \\ ${ }^{3}$ Indian Institute of Chemical Technology, Hyderabad, Telangana, India \\ Email: *venu7000@gmail.com
}

How to cite this paper: Sarma, V.M., Venugopal, N.V.S. and Giribabu, L. (2020) Determination of Lisinopril in Bulk and Pharmaceutical Formulations by Cloud Point Extraction-A Green Method. American Journal of Analytical Chemistry, 11, 289-300. https://doi.org/10.4236/ajac.2020.118023

Received: July 3, 2020

Accepted: August 11, 2020

Published: August 14, 2020

Copyright $\odot 2020$ by author(s) and Scientific Research Publishing Inc. This work is licensed under the Creative Commons Attribution International License (CC BY 4.0).

http://creativecommons.org/licenses/by/4.0/

(c) (i) Open Access

\begin{abstract}
A sensitive and eco-friendly method was developed for the spectrophotometric determination of Lisinopril (LSP) in bulk and pharmaceutical formulations by cloud point extraction technique. The method was based on the formation of a blue-colored coordination complex between Lisinopril (LSP) and Cobalt Thiocyanate (CTC) at a suitable $\mathrm{pH}$. The Complex in aqueous medium was extracted into surfactant layer by cloud point extraction using a non-ionic surfactant Triton X-114 and then the surfactant layer was dissolved in a suitable volume of ethanol and the amount of Lisinopril was determined spectrophotometrically at a wavelength of $625 \mathrm{~nm}$. The conditions like concentration of the drug, concentration of CTC and of Triton X-114, $\mathrm{P}^{\mathrm{H}}$, etc. were optimized by OFAT (One Factor At a Time) method. The linear range of calibration curve was $1-6 \mu \mathrm{g} / \mathrm{ml}$ and the linear regression equation with a correlation coefficient of 0.99996 was $y=0.0021+0.084 x$. Preconcentration and enrichment factors were found to be 100 and 3.12 respectively, achieving the detection limit of $0.0588 \mu \mathrm{g} / \mathrm{ml}$. The proposed method was successfully applied for the determination of LSP in the drug formulations. The obtained values were in agreement with the values as quoted by the manufacturers.
\end{abstract}

\section{Keywords}

Lisinopril (LSP), Cobalt Thiocyanate (CTC), Coordination Complex Formation, Cloud Pint Extraction (CPE), Spectrophotometry

\section{Introduction}

For the body's production of angiotensin II, Angiotensin converting enzyme inhibitors (ACE inhibitors) drugs are applied. It is a hormone that circulates and 
constricts blood vessels and has many effects on the cardiovascular system and sometimes causes heart attack or heart failure. Blocking production of angiotensin II with ACE inhibitors prevents constriction of blood vessels, lowers blood pressure, and weakens the energy the heart has to expend from beat to beat [1] Lisinopril (LSP) is a drug of angiotensin converting enzyme inhibitors class used primarily in the treatment of high blood pressure and heart failures and after heart attacks. Lisinopril is chemically known as $1-\left\{\mathrm{N}^{2}-[(1 \mathrm{~S})-1\right.$-Carboxy 3-Phenyl Propyl]-L-Lysyl\} L-Proline [2] and the structure is shown in Figure 1.

Few methods reported so far includes spectrofluorimetric methods [3] [4] [5], polarographic method [6], high performance liquid chromatography (HPLC) [7], liquid chromatography-mass spectrometry (LC-MS) [8], UV spectroscopy [9], and spectrophotometry [10]-[17]. Determination of drugs by spectrophotometry using Cobalt Thiocyanate (CTC) [18]-[23] was carried out by extracting the drug-CTC complex into an organic solvent like nitrobenzene which is a toxic solvent. Hence a sensitive, low-cost and green method was developed for the spectrophotometric determination of Lisinopril using CTC by cloud point extraction technique. Moreover, there are a few reports available for the determination of drugs by CPE coupled with spectrophotometry [24] [25], spectrofluorometry and RP-HPLC [26] [27] [28] [29] [30]. In the present work, a new, sensitive and green method was developed for the determination of Lisinopril in bulk and pharmaceutical formulations by CPE in combination with UV-Vis spectrophotometry. The method was based on the formation of coordination complex between LSP and CTC at a suitable $\mathrm{pH}$ followed the extraction of the complex by cloud point extraction using Triton X-114 under the optimum conditions. The extracted surfactant layer was dissolved in a little volume of ethanol and the drug was determined by UV-Vis spectrophotometry at $\lambda_{\max }$ of $625 \mathrm{~nm}$. The proposed method was applied for the determination of LSP in pharmaceutical formulations.

\section{Materials and Method}

\subsection{Instrumentation}

The absorption spectra and absorbance values of the selected drug were scanned by using a Systronics-119 double-beam UV-Vis Spectrophotometer with $10-\mathrm{mm}$ superior quality quartz cuvettes. Thermostatic water bath (SISCO, Maharashtra,

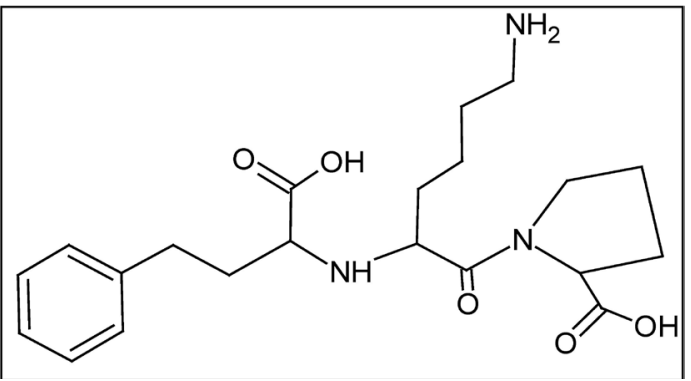

Figure 1. Structure of Lisinopril. 
India), Microprocessor based Laboratory Centrifuge (Laby, India) were used for $\mathrm{CPE}$ procedure. For calibrating the $\mathrm{pH}$ measurements of solutions, digital $\mathrm{pH}$-meter (Analab, India) was used.

\subsection{Reagents and Materials}

A. R. grade chemicals were used in the present work. An aqueous solution $0.5 \mathrm{M}$ of Triton X-114 (obtained from Sigma Aldrich, India) was prepared by dissolving $25.4 \mathrm{ml}$ of Triton X-114 in distilled water to get a final volume of $100 \mathrm{ml}$ solution. A pure grade LSP was supplied by Dr. Reddy's Laboratories, Hyderabad, India. A stock solution of $1 \mathrm{mg} / \mathrm{ml}$ of LSP was prepared by dissolving $100 \mathrm{mg}$ of the drug in distilled water and made up to $100 \mathrm{ml}$. A working solution of 100 $\mu \mathrm{g} / \mathrm{ml}$ was further prepared for analysis. A stock solution of CTC $\left(2.5 \times 10^{-1} \mathrm{M}\right)$ was prepared by dissolving $7.25 \mathrm{~g}$ of cobalt nitrate and $3.8 \mathrm{~g}$ of ammonium thiocyanate in $100 \mathrm{ml}$ of distilled water. Buffer solutions of $\mathrm{pH}$ ranging from 2 to 10 were prepared and calibrated with a digital $\mathrm{pH}$ meter.

\subsection{General Procedure for CPE}

Aliquot of working standard solution of LSP was transferred into a $15 \mathrm{ml}$ graduated centrifuge tube and $3.0 \mathrm{ml}$ of CTC, $1.0 \mathrm{ml}$ of buffer $(\mathrm{pH}=2.0)$ and $1.0 \mathrm{ml}$ of $0.5 \mathrm{M}$ Triton X-114 were added and diluted with distilled water up to $10 \mathrm{ml}$. The solution was shaken thoroughly and then kept for $30 \mathrm{~min}$ in the thermostatic bath at $40^{\circ} \mathrm{C}$. The separation of the phases was further carried out by centrifugation at $4000 \mathrm{rpm}$ for $8 \mathrm{~min}$. The phases were cooled down in an ice water bath for 10 minutes. The layers were separated by inverting the tube. The surfactant-rich layer containing the complex was dissolved with suitable volume of ethanol and the absorbance of the complex measured at $625 \mathrm{~nm}$ against a reagent blank prepared under similar conditions.

\subsection{Procedure for the Tablets}

Four tablets of Listril (Manufactured by Torrent Pharmaceuticals Ltd., India) each containing 2.5 milligrams of LSP were initially crushed, powdered, weighed out and the average weight of one tablet was determined. An accurate weight equivalent to $2.5 \mathrm{mg}$ of LSP was dissolved in $25 \mathrm{ml}$ distilled water and then filtered. Aliquot of this solution was taken within the calibration range and then analyzed as described under the general procedure. The drug content of the tablet was assayed from the calibration curve.

\section{Results and Discussion}

\subsection{Absorption Spectra}

The absorption spectrum of LSP-CTC Complex after cloud point extraction with Triton X-114 was scanned between 500 and $800 \mathrm{~nm}$. The blue colored complex shows that the absorption maximum at $\lambda_{\max }$ of $625 \mathrm{~nm}$ in visible region as shown 
in Figure 2. Thus the wavelength of maximum absorbance at $625 \mathrm{~nm}$ was chosen for the present study.

\subsection{Optimization of Parameters that Affect CPE}

All the important factors that affect the CPE efficiency of the drug LSP were sequentially investigated by OVAT method via changing one factor while keeping other factors constant. In this respect, the effect of $\mathrm{pH}$, concentration of CTC, of non-ionic surfactant Triton X-114, temperature and centrifugation speed and time were optimized.

\subsection{Effect of CTC Concentration}

The effect of concentration of CTC on the absorbance of LSP-CTC complex in the presence of Triton X-114 was studied by recording the absorbance of the complex at $\lambda_{\max }(625 \mathrm{~nm})$ over the range of $1.0-6.0 \mathrm{ml}$ of CTC $\left(2.5 \times 10^{-1} \mathrm{M}\right)$ while keeping the concentrations of LSP, buffer $(\mathrm{pH}=2.0)$ and Triton X-114 constant. The results showed that the absorbance of complex in the surfactant layer increased as shown in Figure 3 with increasing CTC concentration with subsequent increase of absorbance in the aqueous layer also. It indicates that the CTC itself interferes with the absorbance of the complex as its concentration increases in the aqueous layer. $3.0 \mathrm{ml}$ of CTC $\left(2.5 \times 10^{-1} \mathrm{M}\right)$ was selected as its optimum concentration.

\subsection{Effect of $\mathrm{pH}$}

In order to study the effect of $\mathrm{pH}$ on the extraction efficiency of the complex, the solutions containing LSP, CTC, and Triton X-114 were subjected to cloud point extraction by varying the $\mathrm{pH}$ of the solutions in the range of $2-10$. The study showed that the absorbance and extraction efficiency of the complex decreased as shown in Figure 4 from $\mathrm{pH} 2.0$ to $\mathrm{pH} 7.0$ and then increased from $\mathrm{pH} 7.0$ to $\mathrm{pH}$ 10.0. Since maximum efficiency was achieved at $\mathrm{pH} 2.0$, this $\mathrm{pH}$ was selected for CPE procedure.

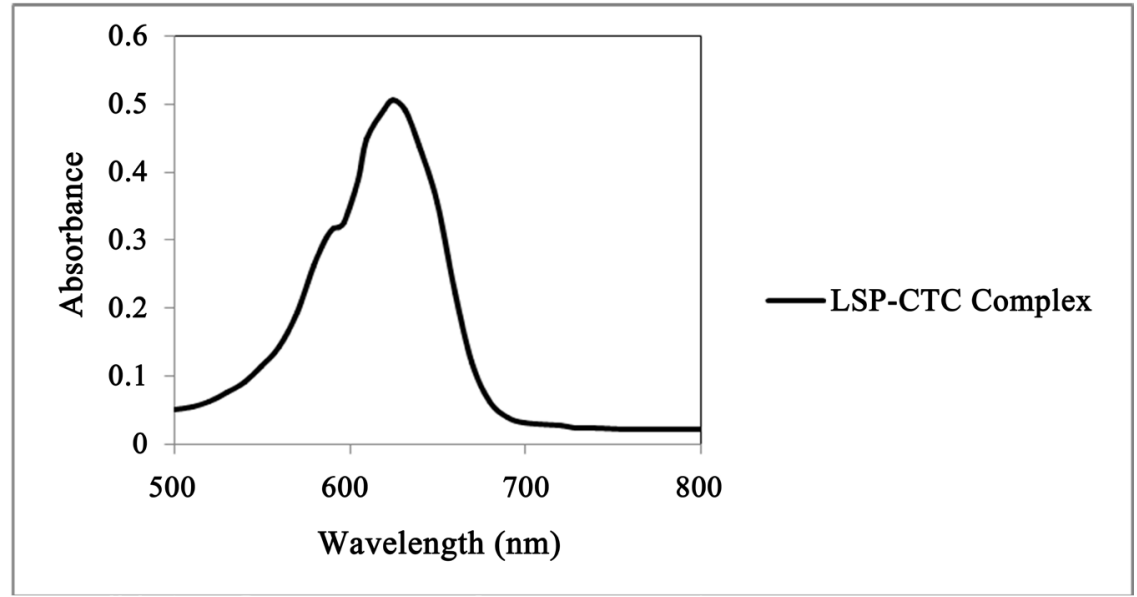

Figure 2. Absorption spectra of LSP-CTC complex. 


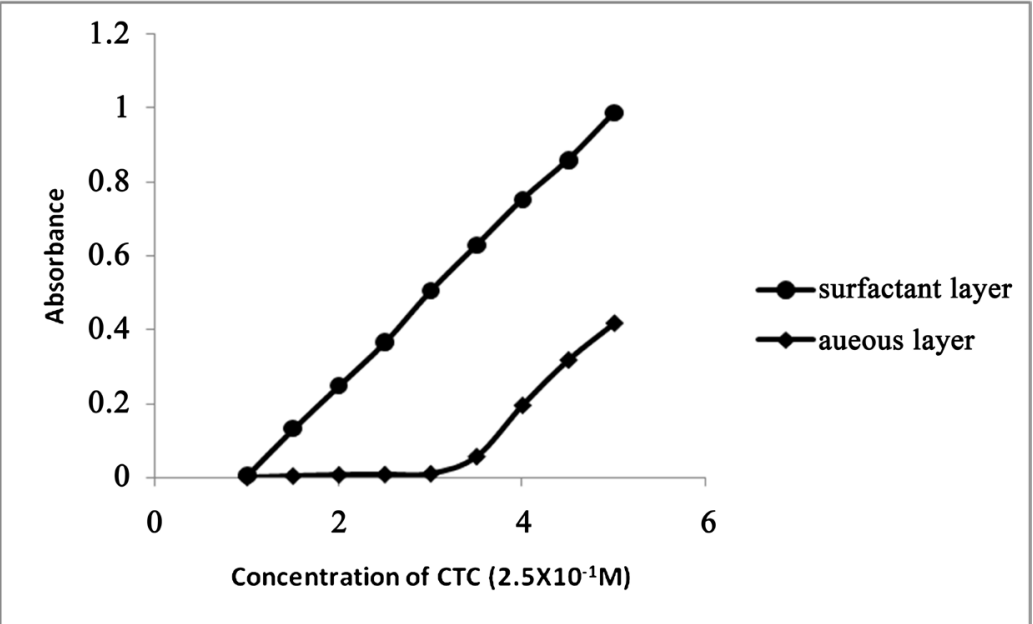

Figure 3. Effect of CTC concentration on the absorbance of the complex.

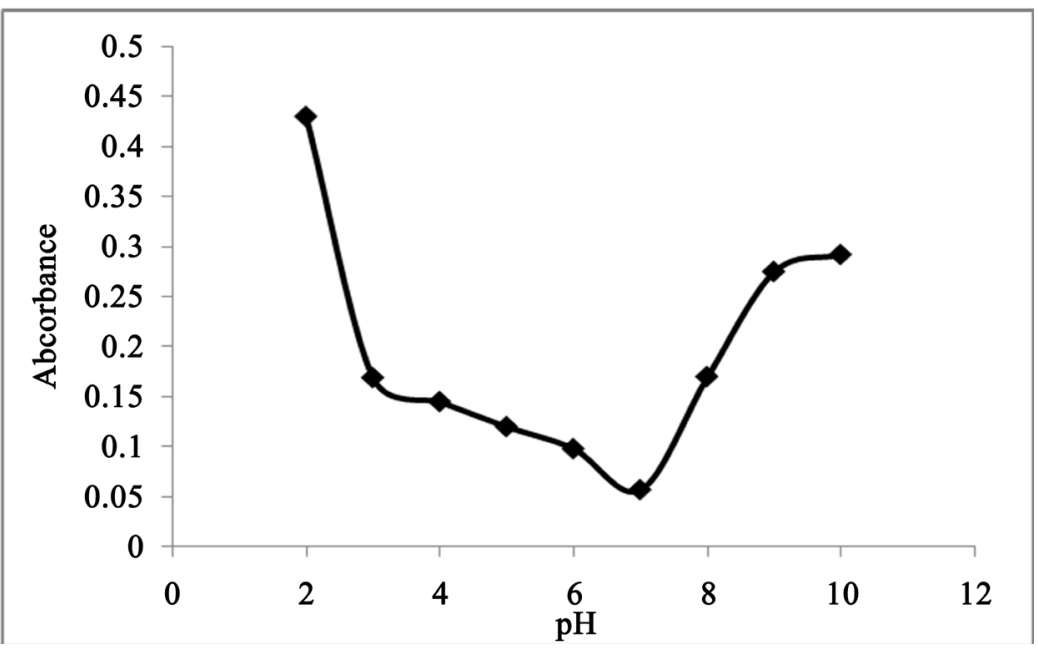

Figure 4. Effect of $\mathrm{pH}$ on the absorbance of the complex.

\subsection{Effect of Triton X-114 Concentration}

The influence of Triton X-114 concentration on the absorbance was studied by varying the concentration of it in the range of $0.01 \mathrm{M}$ to $0.13 \mathrm{M}$ in the CPE procedure. The absorbance of the complex gradually increased as shown in Figure 5 with the increase in the concentration of Triton X-114 up to $0.05 \mathrm{M}$ and then decreased (Figure 5 \& Figure 6). $0.05 \mathrm{M}$ concentration of the surfactant was chosen for the study.

\subsection{Effect of Triton X-114 Concentration on Extraction Efficiency, Preconcentration Factor and Phase Volume Ratio}

The effect of Triton X-114 on the \% extraction efficiency was studied. It was observed that the \% extraction efficiency gradually increased with the increase of Triton X-114 concentration up to $0.05 \mathrm{M}$ and then decreased as shown in the Figure 6. The effect of the surfactant concentration on the Preconcentration factor and phase-volume ratio was also studied and the results were shown the 
Figure 7.

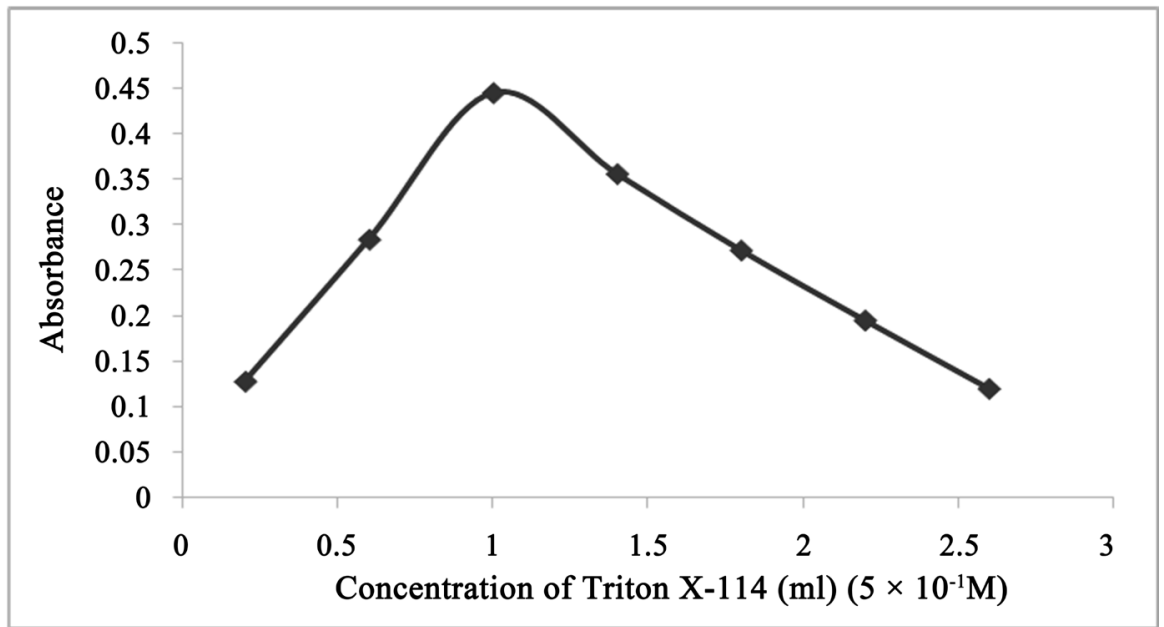

Figure 5. Effect of Triton X-114 on the absorbance of the complex.

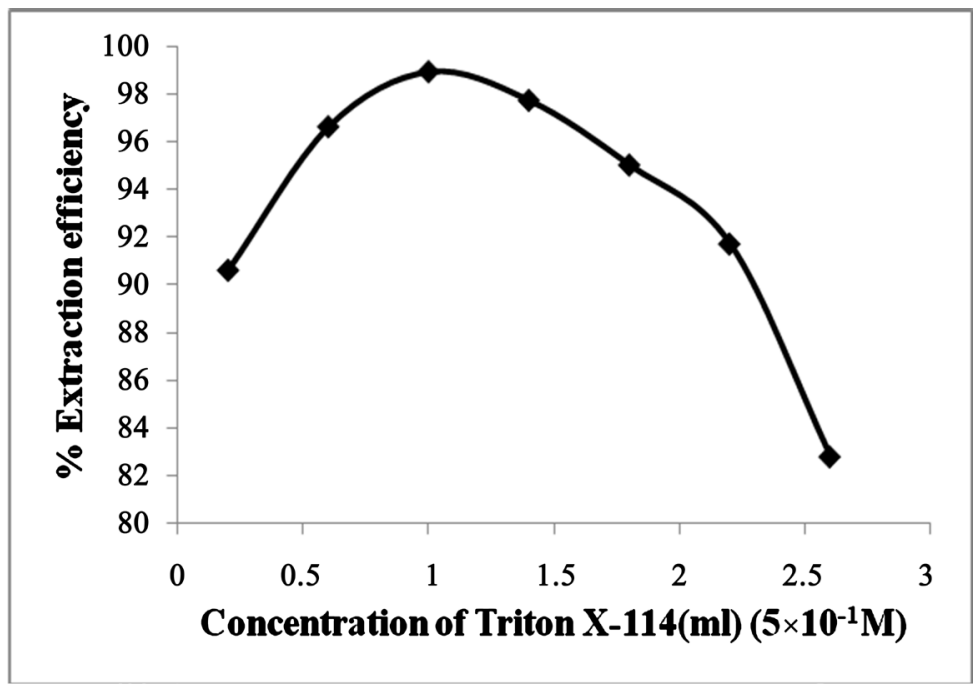

Figure 6. Effect of Triton X-114 on the \% extraction efficiency.

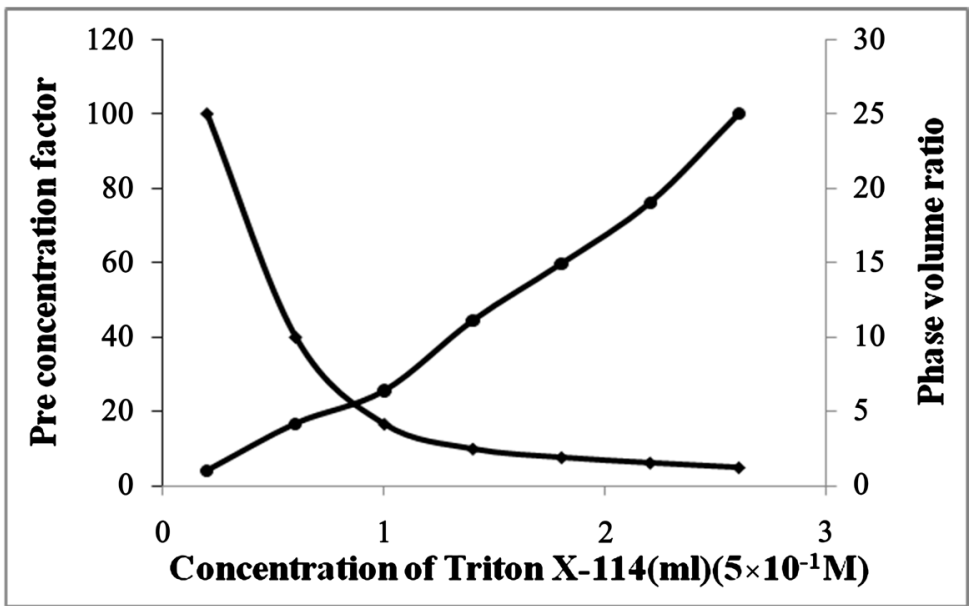

Figure 7. Effect of Triton X-114on the Preconcentration factor and phase volume ratio. 


\subsection{Effect of Incubation Temperature and Time}

It is desirable to employ the incubation temperature and time as low as possible to achieve complete separation of phases and to improve the efficiency of CPE. The effect of incubation temperature was studied in the range of $30^{\circ} \mathrm{C}-60^{\circ} \mathrm{C}$ and $40^{\circ} \mathrm{C}$ was found to be sufficient for complete extraction. Similarly the incubation time was also evaluated in the range of $10-50 \mathrm{~min}$. and for the completion of extraction. $30 \mathrm{~min}$. time was found enough.

The influence of centrifuge time and speed on CPE were also studied in the range of $2-10 \mathrm{~min}$. and $2000-5000 \mathrm{rpm}$ respectively. It was found that $8 \mathrm{~min}$. time and $4000 \mathrm{rpm}$ speed were sufficient to achieve complete extraction.

\subsection{Principle of the Method}

Cobalt Thiocyanate (CTC) has been proved to be a valuable chromogen for the determination of amino compounds. Lisinopril has a secondary amino group and hence it was believed that the $2^{\circ}$ amino group of the drug was coordinated to the $\mathrm{Co}^{+2}$ of CTC as shown in Figure 8 in the following scheme.

\subsection{Calibration Curve of the Proposed Method}

A series of standard of LSP solutions ranging from $1-6 \mu \mathrm{g} / \mathrm{ml}$ were taken and subjected to the general CPE and the absorbance of each solution was measured at $\lambda_{\max }$ of $625 \mathrm{~nm}$, in order to construct the calibration curve as shown in Figure 9 from which the amount of LSP was determined. The calibration curve of the proposed method was given below.

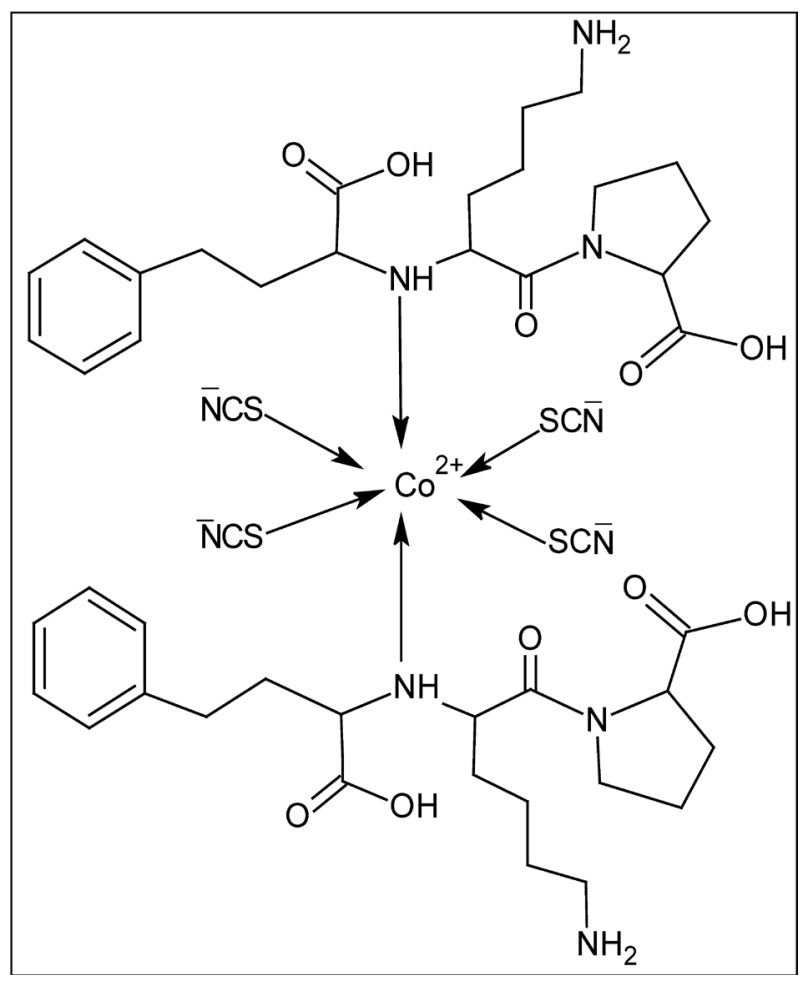

Figure 8. Coordination complex between LSP and CTC. 


\subsection{Evaluation of Calibration Curve}

The statistical data obtained from the calibration curve were tabulated in Table 1.

\subsection{Accuracy and Precision}

Intra-day and inter-day was considered for the calculation of precision. Three concentrations of the drug were analyzed in six replicates during the same day (intra-day precision) and for three consecutive days (inter-day precision). Table 2 and Table 3 given below illustrates the analytical results. For the quality control analysis of the studied drug, the reported precision was adequate and relative standard deviation percentage (RSD\%) was satisfactory.

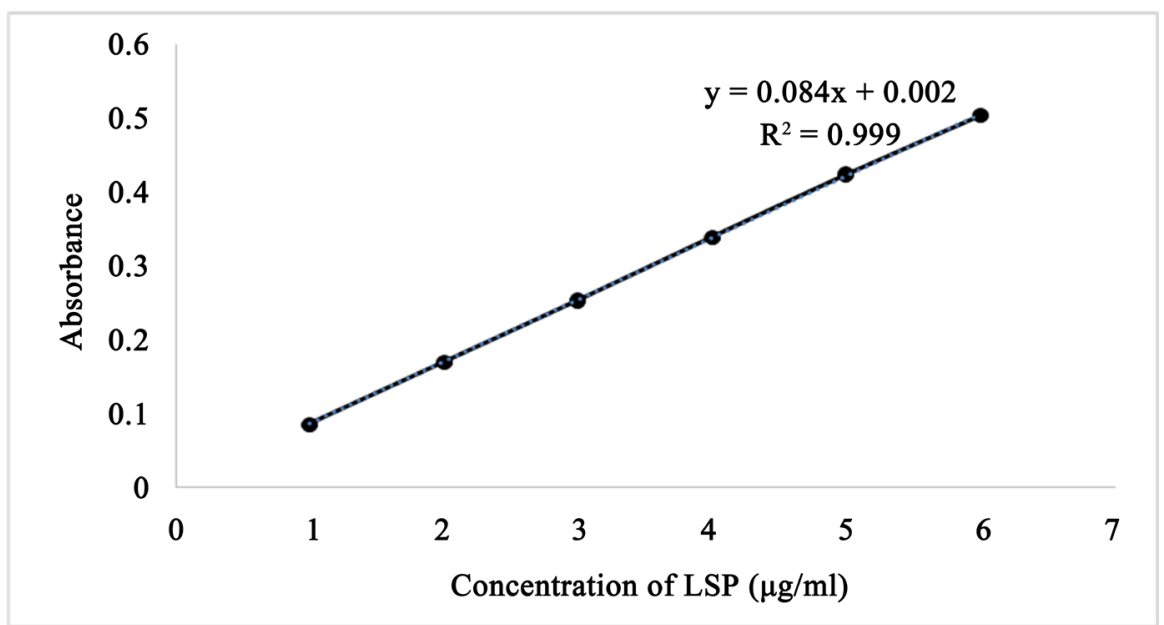

Figure 9. Calibration curve of the proposed method.

Table 1. Statistical data.

\begin{tabular}{|c|c|}
\hline Parameter & value \\
\hline$\lambda_{\max }$ & $625 \mathrm{~nm}$ \\
\hline Beer's Law limits & $1-6 \mu \mathrm{g} / \mathrm{ml}$ \\
\hline Molar absorptivity $\left(\mathrm{L} \cdot \mathrm{mol}^{-1} \cdot \mathrm{cm}^{-1}\right)$ & $3.53 \times 10^{5}$ \\
\hline Sandell's sensitivity $\left(\mu \mathrm{g} \cdot \mathrm{cm}^{-2} / 0.001 \mathrm{~A} . \mathrm{U}\right)$ & 0.0115 \\
\hline Regression equation & $y=0.0842 x+0.0021$ \\
\hline Correlation coefficient (r) & 0.9999 \\
\hline Coefficient of determination $\left(\mathrm{R}^{2}\right)$ & 0.9998 \\
\hline Std.error of regression $\left(\mathrm{s}_{\mathrm{e}}\right)$ & 0.00165 \\
\hline Std.error of slope $\left(\mathrm{s}_{\mathrm{b}}\right)$ & 0.000395 \\
\hline Limit of Detection $(\mu \mathrm{g} / \mathrm{ml})$ & 0.0588 \\
\hline Limit of Quantization ( $\mu \mathrm{g} / \mathrm{ml})$ & 0.1964 \\
\hline Preconcentration factor & 100 \\
\hline $\mathrm{RSD} \%(\mathrm{n}=6)$ at $5 \mu \mathrm{g} / \mathrm{ml}$ & 0.51 \\
\hline
\end{tabular}


Table 2. Analytical results (Intraday).

\begin{tabular}{lccccc}
\hline & & \multicolumn{4}{c}{ Intraday accuracy and precision } \\
\cline { 3 - 5 } Drug & Taken $\left(\mu \mathrm{g} \cdot \mathrm{ml}^{-1}\right)$ & Found $\left(\mu \mathrm{g} \cdot \mathrm{ml}^{-1}\right)$ & Recovery \% & \% RSD & RE \% \\
\cline { 3 - 6 } & 5.0 & 4.996 & 99.92 & 0.51 & -0.078 \\
LSP & 5.0 & 4.992 & 99.8 & 0.69 & -0.0667 \\
& 5.0 & 4.978 & 99.57 & 0.43 & -0.044 \\
\hline
\end{tabular}

Table 3. Analytical results (Interday).

\begin{tabular}{lccccc}
\hline \multirow{2}{*}{ Drug } & Taken $\left(\mu \mathrm{g} \cdot \mathrm{ml}^{-1}\right)$ & \multicolumn{4}{c}{ Interday accuracy and precision } \\
\cline { 3 - 6 } & 5.0 & Found $\left(\mu \mathrm{g} \cdot \mathrm{ml}^{-1}\right)$ & Recovery \% & $\%$ RSD & RE \% \\
\hline \multirow{2}{*}{ LSP } & 5.996 & 99.92 & 0.51 & -0.078 \\
& 5.0 & 5.0 & 100 & 0.66 & 0.00 \\
& 5.0 & 5.03 & 100.67 & 0.34 & 0.67 \\
\hline
\end{tabular}

Table 4. Assay of Lisinopril drug in pharmaceutical formulations.

\begin{tabular}{ccccc}
\hline Formulation/Tablet Labeled amount (mg/Tablet) & Amount found (mg) & \% recovery & \% RSD \\
\hline LISTRIL & 2.5 & 2.495 & 99.8 & 0.45 \\
CIPRIL 5 & 5 & 5.02 & 100.3 & 0.90 \\
\hline
\end{tabular}

\subsection{Determination of LSP in Pharmaceutical Formulations by Proposed Method}

The proposed method was also employed for the determination of LSP content in two selected tablets containing LSP such as Listril (Torrent Pharmaceuticals Ltd. India) and Cipril 5 (Cipla, India) with stated values of $2.5 \mathrm{mg}$ and $5 \mathrm{mg}$ respectively. The results are tabulated in Table 4 . The results obtained are satisfactorily accurate and precise as indicated by the excellent\% recovery. It was found that the excipients and other active ingredients present in pharmaceutical formulations did not interfere with the proposed method.

\section{Conclusion}

The new spectrophotometric method developed for the determination of LSP is more sensitive, reproducible and less expensive when compared to other spectrophotometric methods reported. The developed $\mathrm{CPE}-$ spectrophotometric method was characterized with simplicity, good sensitivity, and low detection limit and reliable for the determination of LSP. In comparison with the existing visible spectrophotometric methods for the determination of LSP, the present modified method can be considered green as it makes use of spectrophotometry without the usage of organic solvent. 


\section{Acknowledgements}

The author is grateful to UGC-SERO, Hyderabad, and Telangana, India for providing financial assistance for the research work carried out. The author also expresses his gratitude to Sri B. V. R. Bhaskar, Dr. Reddy's Laboratories for sending bulk drug samples for his work.

\section{Conflicts of Interest}

The authors declare no conflicts of interest regarding the publication of this paper.

\section{References}

[1] https://www.mayoclinic.org/diseases-conditions/high-blood-pressure/in-depth/aceinhibitors/art-20047480

[2] USP29-NF24. p. 1262.

[3] Zacharis, C.K., Tzanavaras, P.D., Themelis, D.G., Theodoridis, G.A., Economou, A. and Rigas, P.G. (2004) Rapid Spectrofluorimetric Determination of Lisinopril in Pharmaceutical Tablets Using Sequential Injection Analysis. Analytical and Bioanalytical Chemistry, 379, 759-763. https://doi.org/10.1007/s00216-004-2530-4

[4] Aktas, E.S., Ersoy, L. and Sagırl, O. (2003) A New Spectrofluorimetric Method for the Determination of Lisinopril in Tablets. Farmaco, 58, 165-168. https://doi.org/10.1016/S0014-827X(02)00013-7

[5] El-Gindy, A., Ashour, A., Abdel-Fattah, L. and Shabana, M.M. (2001) Spectrophotometric, Septrofluorimetric and LC Determination of Lisinopril. Journal of Pharmaceutical and Biomedical Analysis, 25, 913-922. https://doi.org/10.1016/S0731-7085(01)00376-4

[6] Abdel Razak, O., Belal, S.F., Bedair, M.M., N.S. Barakat and Haggag, R.S. (2003) Spectrophotometric and Polarographic Determination of Enalapril and Lisinopril Using 2,4-Dinitrofluorobenzene. Journal of Pharmaceutical and Biomedical Analysis, 31, 701-711. https://doi.org/10.1016/S0731-7085(02)00654-4

[7] Beasley, C.A., Shaw, J., Zhao, Z. and Robert, A. (2005) Development and Validation of a Stability Indicating HPLC Method for Determination of Lisinopril, Lisinopril Degradation Product and Parabens in the Lisinopril Extemporaneous Formulation. Journal of Pharmaceutical and Biomedical analysis, 37, 559-567. https://doi.org/10.1016/j.jpba.2004.11.021

[8] Zhang, Z., Tian, Y., Xu, F., Wang, N. and Chen, Y. (2007) Rapid Quantification of Lisinopril in Human Plasma by Liquid Chromatography/Tandem Mass Spectrometry. Biomedical Chromatography, 21, 415-421. https://doi.org/10.1002/bmc.774

[9] Özer, D. and Senel, H. (1999) Determination of Lisinopril from Pharmaceutical Preparations by Derivative UV Spectrophotometry. Journal of Pharmaceutical and Biomedical Analysis, 21, 691-695. https://doi.org/10.1016/S0731-7085(99)00168-5

[10] Paraskevas, G., Atta-Politou, J. and Koupparis, M. (2002) Spectrophotometric Determination of Lisinopril in Tablets Using 1-Fluoro-2,4-Dinitrobenzene Reagent. Journal of Pharmaceutical and Biomedical Analysis, 29, 865-872. https://doi.org/10.1016/S0731-7085(02)00207-8

[11] Raza, A., Ansari, T.M. and Atta-Ur-Rehman (2005) Spectrophotometric Determination of Lisinopril in Pure and Pharmaceutical Formulations. Journal of the Chinese Chemical Society, 52, 1055-1059. https://doi.org/10.1002/jccs.200500149 
[12] Jamakhandi, C.M., Javali, C.J., Disouza, I., Chougule, U.S. and Mullani, A.K. (2011) Spectrophotometric Determinationlisinopril Dosage Form by Condensation Reaction. International Journal of Pharmacy and Pharmaceutical Sciences, 3, 185-187.

[13] Nafisur, R., Manisha, S. and Nasrul, H. (2005) Optimized and Validated Spectrophotometric Methods for the Determination of Lisinopril in Pharmaceutical Formulations Using Ninhydrin and Ascorbic Acid. Journal of the Brazilian Chemical Society, 16, 1001-1009. https://doi.org/10.1590/S0103-50532005000600018

[14] Rajasekaran, A. and Udayavani, S. (2001) Spectrophotometric Determination of Lisinopril in Pharmaceutical Formulations. Journal of the Indian Chemical Society, 78, 485-486.

[15] Razak, O.A., Belal, S.F., Bedair, M.M., Barakat, N.S. and Haggag, R.S. (2003) Spectrophotometric and Polarographic Determination of Enalapril and Lisinopril Using 2,4-Dinitrofluorobenzene. Journal of Pharmaceutical and Biomedical Analysis, 31, 701-711. https://doi.org/10.1016/S0731-7085(02)00654-4

[16] Çetin, G. and Sungur, S. (2005) A Spectrophotometric Method for the Determination of Lisinopril in Tablet Formulation. Reviews in Analytical Chemistry, 25, 1-10. https://doi.org/10.1515/REVAC.2006.25.1.1

[17] Siddiqui, M.A. and Azmi, S. N. H. (2007) Spectrophotometric Determination of Lisinopril in Commercial Dosage Forms Using N-Bromosuccinimide and Chloranil. Chemia Analityczna, 52, 465-480.

[18] Ayad, M.M., Khalil, H., El Henawee, M. and Hosney, M. (1999) Comprehensive Coordination Chemistry-II from Biology to Nanotechnology. Scientia Pharmaceutica, 67, 241-252.

[19] Sreelakshmi, A., Devala Rao, G. and Sudhakara Sai Babu, G. (2010) Spectrophotometric Methods for the Estimation of Mizolastine in Pharmaceutical Dosage Forms. International Journal of Chemical Sciences, 8, 1301-1307.

[20] Abdel-Gawad, F.M. and El-Guindi, N.M. (1995) Spectrophotometric Determination of Metoclopramide and Oxybuprocaine through Ion Pair Formation with Thiocyanate and Molybdenum(V) or Cobalt(II). Analytical Letters, 28, 1437-1447. https://doi.org/10.1080/00032719508006405

[21] Raghubabu, K. and Sandhyarani, K. (2015) Estimation of Lisinopril Dihydrate in Bulk and Pharmaceutical Preparations by Visible Spectrophotometry. Journal of Chemical and Pharmaceutical Research, 7, 636-639.

[22] Babu, K.R., Sekhar, D.C., Kumari, N. and Rao, V.J. (2015) Novel Spectrophotometric Methods for the Determination of Clopidogrel Bisulphate in Bulk and Pharmaceutical Formulations by Cobalt Thiocyanate and Tpooo. Der Pharmacia Lettre, 7, 241-246.

[23] Murali, D., Neeharika, T. and Rambabu, C. (2013) Spectrophotometric Determination of Nebivolol Hydrochloride in Bulk and Pharmaceutical Formulations. Asian Journal of Chemistry, 25, 2981-2984. https://doi.org/10.14233/ajchem.2013.13459

[24] Al-Ameer Khammas, Z.A. and Mubdir, N.S. (2014) An Eco-Friendly Method for Extraction and Determination of Ciprofloxacin in Blood Serum and Pharmaceuticals. Science Journal of Analytical Chemistry, 2, 47-54.

https://doi.org/10.11648/j.sjac.20140205.11

[25] Zarei, A.Z., Sadeghi, H.B. and Abedin, B. (2013) Selective Cloud Point Extraction for the Spectrophotometric Determination of Cetylpyridinium Chloride in Pharmaceutical Formulations. Iranian Journal of Pharmaceutical Research, 12, 671-677.

[26] Bavili-Tabrizi, A., Naini, S., et al. (2014) Determination of Triamterene in Human Plasma and Urine After Its Cloud Point Extraction. Química Nova, 37, 1182-1187. https://doi.org/10.5935/0100-4042.20140188 
[27] Madej, K. and Persona, K. (2013) Drug Screening in Human Plasma by Cloud-Point Extraction and HPLC. Central European Journal of Chemistry, 11, 94-100. https://doi.org/10.2478/s11532-012-0134-y

[28] Naveed, S. (2014) Analytical Determination of Lisinopril Using UV Spectrophotometer and HPLC: An Overview. Modern Chemistry \& Applications, 2, Article ID 1000137. https://doi.org/10.4172/2329-6798.1000137

[29] Gul1, W., Augustine, Z., khan, S., Saeed, K. and Raees, H. (2017) Methods of Analysis of Lisinopril: A Review. Journal of Bioequivalence \& Bioavailability, 9, 331-335.

[30] Nasir, I, Musa, A., Abdullahi, M.I. and Garba, M. (2017) Spectrophotometric Determination of Lisinopril in Three Simulated Physiological Fluids. Journal of Pharmaceutical and Allied Sciences, 14, 2638-2645. 